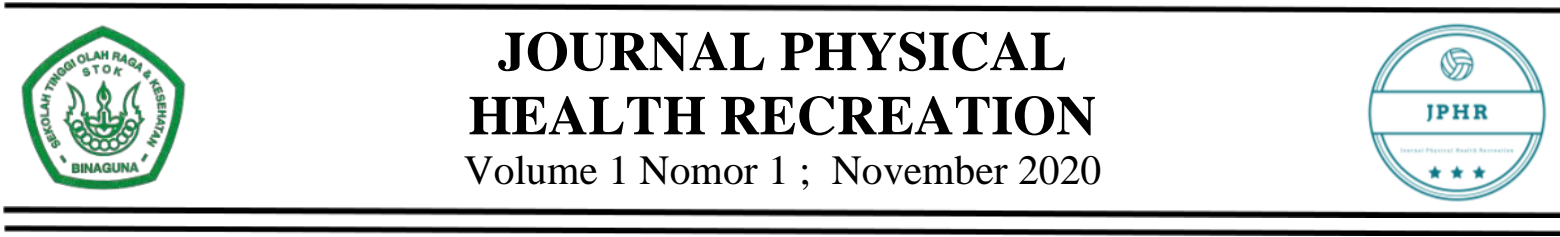

\title{
SURVEY ON THE ABILITY OF PASSING UNDER VOLIARY OF GRADE VIII STUDENTS OF 24 MEDAN SMP NEGERI, 2020
}

\section{SURVEI KEMAMPUAN PASSING BAWAH BOLA VOLI SISWA KELAS VIII SMP NEGERI 24 MEDAN TAHUN 2020}

\author{
Muhammad Aditya ${ }^{1}$, Dewi Maya Sari ${ }^{2}$ \\ Sekolah Tinggi Olahraga dan Kesehatan Bina Guna \\ Jl. Alumunium Raya, Sumatera Utara, 20241, Indonesia
}

\begin{abstract}
ABSTRAK
Penelitian ini bertujuan untuk memperoleh jawaban atas permasalahan tentang survei kemampuan siswa SMP Negeri 24 Medan terhadap permainan kemampuan passing bawah bola voli. Populasi penelitian ini adalah seluruh siswa kelas VIII Negeri 24 Medan. Sampel yang digunakan berjumlah 20 orang. Jenis penelitian yang digunakan adalah penelitian deskriptif kuantitatif dan Instrumen penelitian yang digunakan adalah (1) Tes Keterampilan (2) Angket dan (3) Dokumentasi. Pengolahan data penelitian menggunakan statistik deskriptif sedangkan teknik analisis data yang digunakan adalah Persentase (\%). "Cukup" karena sudah ada beberapa siswa yang dapat melakukan Passing dengan benar tetapi masih ada juga beberapa siswa yang masih melakukan kesalahan dalam melakukan passing kesalahan-kesalahan siswa itu dalam melakukan passing ialah siswa belum mampu membuat bola menyebrangi net, karena posisi kaki saat memukul bola tidak sesuai target. Melalui pengolahan data diperoleh hasil keterampilan passing bawah Siswa kelas VIII Negeri 24 Medan berada pada kategori “"sangat kurang” sebesar 0\% (0 siswa), kategori "kurang" sebesar 25\% (5 siswa), kategori "cukup" sebesar 60\% (12 siswa), kategori "baik" sebesar 10\% (2 siswa), "sangat baik" sebesar 5\% (1 siswa).Kata kunci : Media Pantulan Tembok dan Berpasanga, Sepak Bola
\end{abstract}

\section{Kata kunci: Passing, Voli}

\begin{abstract}
This study aims to obtain answers to the problems regarding the survey on the ability of students of SMP Negeri 24 Medan to the game of volleyball passing under ability. The population of this study were all students of class VIII Negeri 24 Medan. The sample used was 20 people. This type of research is descriptive quantitative research and the research instruments used are (1) Skills Tests (2) Questionnaires and (3) Documentation. Research data processing uses descriptive statistics while the data analysis technique used is percentage $(\%)$. "Enough" because there are already some students who can pass correctly but there are also some students who still make mistakes in passing the students' mistakes. in passing, the student has not been able to make the ball cross the net, because the position of the foot when hitting the ball does not match the target. Through data processing, the results of the underpassing skills of Class VIII Negeri 24 Medan students were in the "very poor" category of $0 \%$ (0 students), the "poor" category was $25 \%$ (5 students), the "sufficient" category was $60 \%$ ( 12 students), the "good" category was 10\% (2 students), "very good" was 5\% (1 student). Key words: Wall Reflection and Pairing Media, Football
\end{abstract}




\section{Keywords: passing, volly.}

\section{PENDAHULUAN}

Pengalaman belajar tidak hanya didapat saat dalam proses belajar mengajar saja, tetapi bisa didapatkan pada kegiatan diluar jam pelajaran yang biasa disebut dengan Ekstrakurikuler. Kegiatan ektrakurikuler berfungsi sebagai wahana untuk menampung, menyalurkan, dan membina minat serta kegemaran siswa dalam berbagai bidang. Dalam hal membina minat serta kegemaran siswa dalam berbagai bidang, salah satu bidang yang dikembangkan melalui kegiatan ekstrakurikuler di sekolah adalah bidang olahraga.

Benny Aprial. M, dan Ika Endah Puspita Sari dalam jurnal of Nursing And Midwifery Passing in a volleyball game consists of two (2) types, namely passing above and below passing. Basically two types of passing the same aims to pass the ball to a member of his team to the next is expected to be an attack back to the opposing team. Passing on a ball control techniques that are important to learn. Passing on is a means serving the ball or pass the ball by using your fingers to direct spaciousness friend or opponent, in addition to passing on the good will affect in the game but it is more pronounced in high-level games than at a lower game.

Fungsi dan kedudukan olahraga itu sendiri selalu berubah-ubah. Hal ini disebabkan oleh kondisi-kondisi obyektif dan subyektif yang ada pada suatu masa dan di sebabkan pula oleh pandangan hidup dan moralitas yang berbeda-beda, baik yang berlaku pada suatu masa atau yang berlaku pada suatu bangsa. Tetapi hakikat dari suatu olahraga itu sendiri tidak berubah-ubah. Adapun tujuan dari olahraga antara lain sebagai profesi, kerja, rekreasi, kesehatan, prestasi, bisnis, alat pemersatu, dan alat perjuangan.

Dalam kegiatan Pembelajaran Praktik bola voli di SMP Negeri 24 Medan, bermacam-macam bentuk kegiatan yang diberikan mulai dari kemampuan dasar, taktik, dan teknik bertanding bola voli yang sebenarnya. Agar dapat menguasai teknik dasar bermain bola voli diperlukan waktu yang cukup lama untuk berlatih. Masing-masing siswa membutuhkan waktu yang berbeda-beda dalam penguasaan suatu teknik dasar. Bakat, minat, dan kedisiplinan dalam berlatih sangat menetukan dalam penguasaan kemampuan dasar bermain bolavoli.

Pada silabus SMP Negeri 24 Medan ini membahas materi tentang bola voli yaitu, Passing bawah, Passing atas, Servis bawah, Servis atas, Smas/spike, Block/ bendungan. Peserta didik menerima dan mempelajari kartu tugas (task sheet) yang berisi perintah dan indikator tugas gerak spesifik permainan bolavoli (gerak passing bawah, passing atas, servis bawah, servis atas, smes/spike, bendungan/blocking). Peserta didik melaksanakan tugas ajar sesuai dengan target waktu yang ditentukan guru untuk mencapai ketuntasan belajar pada setiap materi pembelajaran Peserta didik menerima umpan balik dari guru. Peserta didik melakukan pengulangan pada materi pembelajaran yang belum tercapai ketuntasannya sesuai umpan balik yang diberikan. Peserta didik mencoba tugas gerak spesifik permainan bolavoli ke dalam permainan sederhana dan atau tradisional dilandasi nilai-nilai disiplin, sportif, kerja sama, dan percaya diri.

Berdasarkan observasi, terdapat beberapa siswa masih salah dalam melakukan passing bawah, baik dari sikap awal, sikap perkenaan, maupun sikap akhir. Masih banyak siswa yang belum mampu melakukan gerak dasar permainan bolavoli dengan benar, khususnya melakukan passing bawah dengan kesalahan yang sering terjadi, yaitu siswa melakukan passing bawah dengan lengan bengkok karena siku ditekuk dan kesalahan pada sikap awalan, yaitu sikap tubuh tegak dengan sikap kaki dirapatkan atau mengangkang terlalu lebar sehingga sikap awalan posisi kaki tidak kuda-kuda (depan belakang). Pada saat kegiatan ekstrakurikuler 
berlangsung, lebih banyak permainan atau games, sehingga latihan terkesan monoton. Latihan yang mengarah ke teknik, khususnya teknik passing bawah sangat jarang dilakukan, bahkan hampir tidak pernah. Permasalahan yang terkait dengan pembelajaran passing bawah bola voli sangat kompleks.

\section{METODE PENELITIAN}

Penelitian ini termasuk penelitian deskriptif kuantitatif. Penelitian deskriptif maksudnya penelitian ini hanya ingin mendeskripsikan atau memaparkan situasi yang sedang berlangsung pada saat penelitian diadakan dan tidak bermaksud menguji hipotesis. Metode yang dilakukan dalam penelitian ini adalah metode survey dengan teknis tes dan pengukuran. Untuk mengetahui data secara nyata digunakan tes kemampuan teknik dasar passing bawah bolavoli. Unsur penilaian tes kemampuan passing bawah yang mengacu pada teknik dasar passing bawah bola voli oleh Depdiknas (1999: 7-14).

Sampel yang diambil dalam penelitian ini adalah 50\% dari jumlah populasi yang ada dengan memilih secara random kelas yang sudah diberikan nomor untuk di jadikan sampel,.Mengigat populasi dalam penelitian ini yakni siswa SMP Negeri 24 Medan bahwa pengambilan sampel dilakukan pada semua populasi yang ada, sehingga di peroleh sampel 20 orang siswa.

Populasi adalah wilayah generalisasi yang terdiri atas subjek/objek yangmempunyai kuantiatas dan karakteristik tertentu yang ditetapkan peneliti untuk dipelajari dan kemudian ditarik kesimpulan Sugiyono (2010: 117). Populasi penelitian ini adalah seluruh siswa Kelas VIII SMP Negeri 24 Medan yang berjumlah 268 siswa yang terdiri dari 9 kelas.

\section{HASIL DAN PEMBAHASAN}

Distribusi frekuensi data hasil penelitian tentang keterampilan passing bawah Siswa kelas VIII di SMP Negeri 24 Medan didapat skor rata-rata terendah (minimum) 60, skor tertinggi (maksimum) 83, rerata (mean) 70,9 standar deviasi (SD) 6,938, distribusi frekuensi.

Penelitian ini bertujuan untuk mengetahui tingkat kemampuan passing bawah Siswa kelas VIII di SMP Negeri 24 Medan. Berdasarkan hasil analisis tersebut menunjukkan bahwa tingkat kemampuan passing bawah bolavoli Siswa kelas VIII di SMP Negeri 24 Medan dalam kategori cukup. Ada siswa yang sudah dapat melakukan passing dengan baik, tetapi masih banyak siswa yang salah dalam melakukan teknik passing bawah. Siswa tidak mengetahui teknik passing bawah yang baik dan benar, terutama pada sikap awalan dan perkenaan. Pada sikap awalan yang seharusnya posisi badan rendah, kaki ditekuk, akan tetapi banyak siswa yang masih dalam posisi tegap.

Pada sikap perkenaan kebanyakan perkenaan bola tidak tepat, sehingga hasil passing yang dilakukan tidak baik. Passing berarti mengumpan atau mengoper, teknik 
ini adalah teknik dasar yang cukup sulit dan digunakan dalam permainan bolavoli.

Begitu pula dalam pembelajaran penjas, penguasaan passing bawah harus dikuasai oleh seorang siswa. Karena akan menentukan cara bermain siswa dalam permainan bolavoli, karena penerimaan passing yang baik adalah awal dari keberhasilan smash dan apabila passing baik maka permainan akan berjalan dengan baik juga.

Kesalahan maupun cara memperbaiki passing bawah harus diperhatikan oleh guru. Pada umumnya siswa tidak mampu mengamati letak kesalahan yang dilakukan. Seorang guru harus mampu mencermati setiap bentuk gerakan yang dilakukan anak didiknya, sehingga akan diketahui letak kesalahannya. Setiap kesalahan yang dilakukan, guru segera mungkin untuk membetulkan gerakan yang salah, sehingga kualitas passing bawah yang dilakukan hasilnya sesuai yang diharapkan.

Menurut Suharno (1984: 26) passing adalah usaha ataupun upaya seorang pemain bolavoli dengan cara menggunakan suatu teknik tertentu yang tujuannya untuk mengoperkan bola yang dimainkannya itu kepada teman seregunya untuk dimainkan dilapangan sendiri. Dengan adanya passing yang baik maka dapat membuat serangan yang baik ke daerah lawan sehingga dapat menghasilkan skor.

Passing bawah merupakan teknik dasar bolavoli. Teknik ini digunakan untuk menerima servis, menerima spike, memukul bola setinggi pinggang ke bawah dan memainkan bola yang memantul dari net. Passing bawah merupakan awal dari sebuah penyerangan dalam bolavoli. Keberhasilan penyerangan tergantung dari baik buruknya passing bawah. Apabila bola yang dioperkan jelek, maka pengumpan akan mengalami kesulitan untuk menempatkan bola yang baik untuk para penyerang.

Implikasi penelitian ini adalah untuk bahan pertimbangan dalam latihan passing bawah bolavoli di Siswa kelas VIII di SMP Negeri 24 Medan, supaya dalam permainan bisa mencapai hasil yang maksimal. Perbaikan teknik passing bawah Siswa kelas VIII di SMP Negeri 24 Medan yaitu dengan menambah latihan teknik bolavoli supaya semua siswa memiliki teknik yang bagus, khususnya passing bawah dan bisa bermain dengan maksimal. Dalam pembelajaran penjas khususnyaa tehnik dasar kemampuan passing bawah bolavoli siswa kelas VIII di SMP Negeri 24 Medan, siswa kebanyakan lebih tinggi penetaahuaan dibandingkan dengaan peraktek. Sehinggaa siswaa butuh latihan untuk melakukan passing bawah agar siswa kelas VIII di SMP Negeri 24 Medan bisa berprestasi dalam berolahraga.

\section{KESIMPULAN}

Dari hasil analisis data, dekskripsi, pengujian hasil penelitian, dan 
pembahasan, dapat diambil kesimpulan, bahwa kemampuan passing bawah Siswa kelas VIII di SMP Negeri 24 Medan berada pada kategori "Cukup" karena sudah ada beberapa siswa yang dapat melakukan Passing dengan benar tetapi masih ada juga beberapa siswa yang masih melakukan kesalahan dalam melakukan passing kesalahan-kesalahan siswa itu dalam melakukan passing ialah siswa belum mampu membuat bola menyebrangi net, karena posisi kaki saat passing bola tidak sesuai target.

Hal ini dapat dilihat dari perhitungan data yang telah didapatkan sebagai berikut: ketegori "sangat kurang" sebesar $0 \% \quad(0$ siswa), kategori "kurang” sebesar 35\% (7 siswa), kategori "cukup" sebesar 50\% (10 siswa), kategori "baik" sebesar 15\% (3 siswa), "sangat baik" sebesar 0\% (0 siswa).

\section{DAFTAR PUSTAKA}

Agus, Mahendra. (2003). Pemanduan Bakat Olahraga. Jakarta: Depdiknas.

Amung Ma'mun dan Yudha. (2000). Perkembangan Gerak dan Belajar Gerak Jakarta: Depdiknas.

Depdiknas. (2003). Badan Peneliti dan Pengembangan Pusat Kurikulum. Jakarta.Sabaruddin Yunis. 2016. Pengembangan Pengetahuan Anak Difabel Melalui Pendidikan Jasmani Olahraga dan Outbound. Journal Physical Education, Health and Recreation. Vol 1, No 1. Hal 70-77.

M Aprial, Benny dan Ika Endah Puspitasari (2019) Efforts to Improve Learning Outcomes passing Down Volleyball Variations Through Learning and
Modified Ball On Private Junior High School eighth grade students Perbaungan Satria Dharma School Year 2019/2020. In: Journal of Nursing And Midwifery Vol 2, No. 1 December 2019.

Nuril Ahmadi. (2007). Panduan Olahraga Bola Voli. Solo: Era Pustaka Utama. 